\title{
ANALISIS PENGARUH IMPLEMENTASI SISTEM KESELAMATAN KESEHATAN KERJA (K3) TERHADAP UNSAFE ACTION DI PT EGS INDONESIA
}

\author{
Rici Riansyah \\ Magister Manajemen, Fakultas Keselamatan Kesehatan Kerja, Universitas Sahid Jakarta \\ riciriansyah.rr@gmail.com
}

\begin{abstract}
Work accident occur because of two groups. The first group is mechanical and environmental factors (unsafe conditions). The second group is the human factor (unsafe action). Human resources are very important assets in a company or organization, where employees can become potentials if managed properly and properly. On the contrary, it can become a burden if you are mismanaged. One of the efforts that companies can make to maintain employee health and safety is to implement employee health and safety management by implementing a good and correct application of an occupational safety and health management system (SMK3). Unsafe acts at PT EGS Indonesia. This type of research is descriptive quantitative with the approach used is cross sectional. The data analysis technique used in this research is Structural Equation Model (SEM). The results showed that the OSH management system in the form of leadership and policy had a negative effect on unsafe action. The OSH Management system in the form of planning has a negative effect on unsafe actions. The OSH management system in the form of its implementation has a negative effect on unsafe actions. The OSH Management system in the form of performance evaluation has a negative effect on unsafe actions. The OSH management system in the form of corrective action has a negative effect on unsafe actions. The conclusion is that the overall occupational health safety management system in the form of leadership and policies, planning, implementation, performance evaluation and corrective action has a negative effect on unsafe action.
\end{abstract}

Keywords $\quad$ : Work Accident, Unsafe Condition, Unsafe Action, OSH, Structural Equal Models

\begin{abstract}
ABSTRAK
Kecelakaan kerja terjadi karena dua golongan. Golongan pertama adalah faktor mekanis dan lingkungan (unsafe condition). Golongan kedua adalah faktor manusia (unsafe action). Sumber daya manusia merupakan aset yang sangat penting dalam suatu perusahaan atau organisasi, karyawan dapat menjadi potensi bila dikelola dengan tepat dan benar. Sebaliknya, sumber daya manusia dapat menjadi beban jika salah dalam mengelolanya. Salah satu upaya yang dapat dilakukan perusahaan untuk menjaga kesehatan dan keselamatan kerja karyawan ialah dengan melakukan penerapan manajemen kesehatan dan keselamatan kerja karyawan dengan pelaksanaan penerapan Sistem Manajemen Kesehatan Keselamatan Kerja (SMK3) yang baik dan benar. Penelitian ini bertujuan untuk mengetahui pengaruh implementasi SMK3 terhadap unsafe action di PT EGS Indonesia. Jenis penelitian bersifat deskriftif kuantitatif dengan pendekatan yang digunakan adalah cross sectional. Teknik analisis data yang digunakan adalah SEM. Hasil penelitian menunjukkan Sistem manajemen K3 berupa kepemimpinan dan kebijakan memiliki pengaruh ngeatif terhadap unsafe action. Sistem manajemen K3 berupa perencanaan memiliki pengaruh negatif terhadap unsafe action. Sistem manajemen K3 berupa pelaksanaan memiliki pengaruh negatif terhadap unsafe action. Sistem manajemen K3 berupa evaluasi kinerja memiliki pengaruh negatif terhadap unsafe action. Sistem manajemen K3 berupa tindakan perbaikan memiliki pengaruh negatif terhadap unsafe actIon. Adapun kesimpulan secara keseluruhan sistem manajemen keselamatan kesehatan kerja berupa kepemimpinan dan kebijakan, perencanaan, pelaksanaan, evaluasi kinerja dan tindakan perbaikan memiliki pengaruh negatif terhadap tindakan tidak aman (unsafe action).
\end{abstract}

Kata Kunci : Kecelakaan Kerja, Unsafe Condition, Unsafe Action, SMK3, Structural Equal Models 


\section{PENDAHULUAN}

Untuk mendukung aktivitas kegiatan perusahaan, pada bulan Desember 2012, PT Energy Gas Survey (EGS) Indonesia telah memperoleh Sistem Manajemen Mutu, Kesehatan, Keselamatan dan Lingkungan (QHSE-MS) sesuai ISO 9001, ISO 14001 dan OHSAS 18001. Untuk OHSAS 18001 khususnya, di tahun ini telah melaksanakan migration ke ISO 45001:2018 mengenai Keselamatan dan Kesehatan Kerja. Dengan adanya sistem K3 yang berjalan, perusahaan berharap sistem ini dapat mencegah terjadinya kasus Lost Tim Injury Frequency Rate (LTIFR) di setiap proyek agar tercapainya zero accident sesuai dengan target perusahaan setiap tahunnya. Adapun berdasarkan informasi yang didapat bahwa perilaku karyawan dapat menjadi faktor utama yang menyebabkan timbulnya unsafe action (tindakan tidak aman) maupun unsafe condition (kondisi tidak aman) di tempat kerja.(Bacchetta, 2007).

Berdasarkan data statistik Quality, Health, Safety, and Environment (QHSE) Performance PT EGS Indonesia selama tiga terakhir, angka kejadian unsafe action maupun unsafe condition masih tergolong cukup tinggi, meskipun cenderung terjadi penurunan setiap tahunnya (Pusat et al., n.d, Bacchetta, 2007). Jumlah kasus unsafe action maupun unsafe condition yang terjadi di tahun 2016 sebanyak 383 kasus, di tahun 2017 sebanyak 135 kasus dan untuk tahun 2018 sebanyak 52 kasus. Adapun untuk fatality selama tiga tahun terakhir tidak pernah terjadi insiden. Begitu juga untuk kejadian first aid maupun environmental accident juga belum pernah ditemukan kasus selama di lapangan. Untuk kejadian nearmiss yang dilaporkan pernah terjadi 1 kali setiap tahunnya yaitu di tahun 2017 dan 2018.

Berdasarkan data tabel 1, peneliti mengambil kesimpulan awal bahwa unsafe action maupun unsafe condition masih menjadi permasalahan yang cukup tinggi di perusahaan, yang nantinya dapat menjadi salah satu faktor penyumbang LTIFR di tempat kerja. Adapun kasus unsafe action maupun unsafe condition yang masih sering terjadi ataupun diabaikan oleh pekerja berupa: penggunaan Alat Pelindung Diri (APD), housekeeping, merokok sembarangan, bekerja tidak sesuai prosedur, dan lain-lain.

Tabel 1. Statistik QHSE Performance di PT EGS INDONESIA 2016-2018

\begin{tabular}{lccc}
\hline \multirow{2}{*}{ Kategori } & \multicolumn{3}{c}{ Tahun } \\
\cline { 2 - 4 } & $\mathbf{2 0 1 6}$ & $\mathbf{2 0 1 7}$ & $\mathbf{2 0 1 8}$ \\
\hline $\begin{array}{l}\text { Unsafe action } \\
\text { \&condition }\end{array}$ & 383 & 135 & 52 \\
\hline Fatality & 0 & 0 & 0 \\
\hline First Aid & 0 & 0 & 0 \\
\hline Near Miss & 0 & 1 & 1 \\
\hline $\begin{array}{l}\text { Environmental } \\
\text { Accident }\end{array}$ & 0 & 0 & 0 \\
\hline
\end{tabular}

Kecelakaan kerja terjadi karena dua golongan. Golongan pertama adalah faktor mekanis dan lingkungan (unsafe condition). Golongan kedua adalah faktor manusia (unsafe action) (Rizka Pisceliya \& Mindayani, 2018). Adapun beberapa penelitian yang dilakukan menunjukkan bahwa faktor manusia berada di posisi yang sangat penting terhadap kejadian kecelakaan kerja yaitu berkisar antara 80-85\%. Salah satu upaya yang dapat dilakukan perusahaan untuk menjaga kesehatan dan keselamatan kerja karyawan ialah dengan melakukan penerapan manajemen kesehatan dan keselamatan kerja karyawan dengan pelaksanaan penerapan SMK3 yang baik dan benar.

Feng et al. (2015) dalam penelitiannya menyatakan terdapat hubungan yang bermakna antara perilaku dengan penerapan manajemen budaya K3. Karyawan yang mempunyai perilaku tidak baik memiliki risiko untuk tidak menerapkan manajemen budaya K3 dibandingkan karyawan yang mempunyai perilaku baik. Dengan adanya sistem K3 yang berjalan, perusahaan berharap sistem ini dapat mencegah terjadinya kasus LTIFR di setiap proyek agar tercapainya zero accident sesuai dengan target perusahaan setiap tahunnya. perilaku pekerja dapat menjadi faktor utama yang 
menyebabkan timbulnya unsafe action (tindakan tidakaman) maupun unsafe condition (tindakan tidak aman) di tempat kerja. Berdasarkan data statistik QHSE Performance PT EGSI selama tiga terakhir, angka kejadian unsafe action maupun unsafe condition masih tergolong cukup tinggi, meskipun cenderung terjadi penurunan setiap tahunnya. Oleh itu penelitian ini dilakukan dengan tujuan untuk mengidentifikasi pelaksanaan sistem keselamatan kesehatan kerja PT EGS Indonesia. Selain itu untuk mengetahui pelaksanaan sistem keselamatan kesehatan kerja terhadap unsafe action di PT EGS Indonesia.

Kecelakaan ini biasanya terjadi akibat kontak dengan suatu zat atau sumber energi. Penyebab kecelakaan kerja berdasarkan sistem manajemen terbagi unsafe action dan unsafe condition. Unsafe action merupakan kegagalan (human failure) dalam mengikuti persyaratan dan prosedur-prosedur kerja yang benar sehingga menyebabkan terjadinya kecelakaan kerja. Sedangkan unsafe condition dimana kondisi-kondisi yang tidak aman dan berbahaya bagi para nekeria.

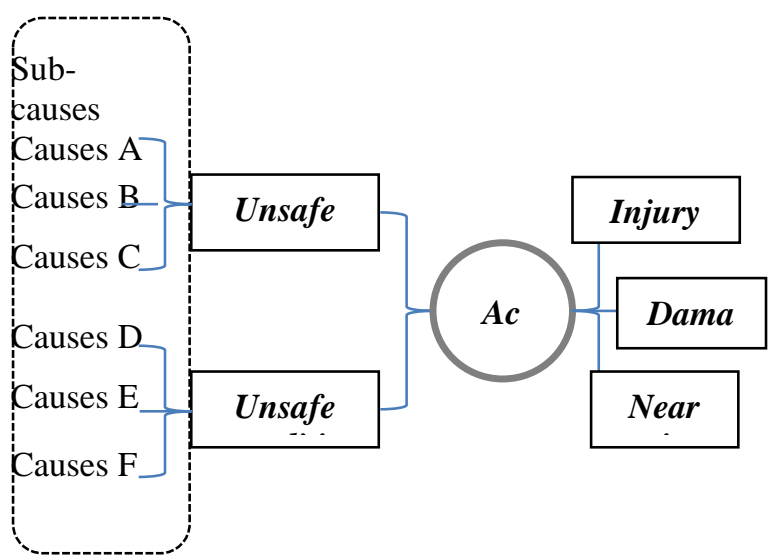

\section{Gambar 1. Multiple Causation Theory}

Pada gambar 1 terlihat bahwa terdapat lebih dari satu penyebab dan sub-penyebab yang dapat menimbulkan kecelakaan kerja. Faktor-faktor yang mempengaruhi terbentuknya tindakan tidak aman (unsafe action) adalah sangat kompleks, dimana didalamnya melibatkan faktor-faktor yang sangat luas, yaitu: manajemen, sosial, psikologis dan human-machine environment system. Meskipun demikian kompleks, namun esensinya adalah ingin menggambarkan bahwa tindakan tidak aman (unsafe action) tidak dapat dilepaskan dari faktor-faktor yang berasal dari manusia sendiri dan lingkungan organisasinya. Tindakan tidak aman (unsafe action) terjadi melalui 3 (tiga) fase yang bekerja secara bertahap, yaitu tingkat manajemen; aspekaspek lingkungan fisik, psikologis dan sosiologis dari pekerjaan; individu.

Perilaku keselamatan dalam keselamatan kerja yang berhubungan langsung dengan perilaku karyawan dalam bekerja demi keselamatan individu sangat berhubungan erat dengan iklim keselamatan dan pengetahuan keselamatan, karena dengan keadaan iklim keselamatan yang ada di dalam perusahaan dapat mempengaruhi tingkat kesehatan karyawan dan dengan adanya pengetahuan keselamatan kerja yang tinggi, maka karyawan mampu mengerti dan memahami arti keselamatan kerja dengan baik. Komponen terpenting dalam menjaga keselamatan jiwa dan keselamatan peralatan kerja adalah pengetahuan tentang penggunaan perlengkapan keselamatan kerja bagi karyawan. Dimana dampak yang dapat dirasakan dari perilaku keselamatan bagi perusahaan adalah produktivitas kerja, (Anam, 2015).

Pelaksanaan SMK3 dalam Peraturan Pemerintah No. 50 Tahun 2012 tersebut dilakukan dengan tujuan untuk meningkatkan efektifitas perlindungan K3 dengan cara terencana, terukur, terstruktur, terintegrasi. Selain itu untuk mencegah kecelakaan kerja dan mengurangi penyakit akibat kerja, dengan melibatkan: manajemen, tenaga kerja/pekerja dan serikat pekerja. SMK3 diwajibkan bagi perusahaan, mempekerjakan lebih dari 100 orang dan mempunyai tingkat potensi bahaya tinggi (UU RI Nomor 1 Tahun 1970, 1970). Penerapan Sistem Manajemen Keselamatan dan Kesehatan Kerja (SMK3) berdasarkan Peraturan Pemerintah RI No. 50 Tahun 2012 yaitu Penetapan Kebijakan K3, Perencanaan K3, Pelaksanaan Rencana K3, Pemantauan 
dan Evaluasi Kinerja K3 serta Peninjauan dan Peningkatan Kinerja SMK3. (Government Regulation Number 50, 2012)

ISO 45001 adalah standar internasional mengenai persyaratan sistem manajemen kesehatan dan keselamatan kerja. Tujuannya adalah untuk membantu organisasi dalam memperbaiki kinerja K3, pencegahan kecelakaan kerja dan meningkatkan kesehatan karyawan. Standar ini bisa diterapkan pada semua organisasi tanpa memperhatikan ukuran, jenis dan sifat pekerjaannya. Melalui sistem manajemen K3 pada standar ini, organisasi dapat mengintegrasikan aspek kesehatan dan keselamatan lain seperti kesehatan kesejahteraan pekerja. Meskipun terdapat beberapa perubahan, tujuan keseluruhan ISO 45001 tetap sama seperti OHSAS 18001, yaitu untuk mengurangi risiko yang tidak dapat diterima dan memastikan keselamatan dan kesejahteraan semua orang yang terlibat dalam kegiatan organisasi. (BSI ISO, 2018)

Standar dapat digunakan secara keseluruhan atau sebagian untuk meningkatkan SMK3 secara sistematis. Standar ISO 45001:2018 terdiri atas 10 klausul yang sama dengan klausul di ISO 9001:2015 dan ISO 14001:2015 sehingga mudah integrasinya. 10 klausul tersebut adalah Ruang Lingkup, Acuan Normatif, Istilah dan Definisi, Konteks Organisasi, Kepemimpinan, Perencanaan, Dukungan, Operasi, Pemeriksaan dan Perbaikan.Konsep dasar ISO 45001:2018 berkaitan dengan hal-hal baru pada klausul ISO 45001:2018 seperti pendekatan proses, pemikiran berbasis resiko, PDCA, konteks organisasi dan resiko \& peluang. (Kementerian Tenaga Kerja, 2012).

ISO 45001: 2018 menggunakan model Plan-Do-Check-Act (PDCA) dalam implementasinya, yang menyediakan kerangka kerja sederhana dan efektif bagi organisasi untuk merencanakan apa yang harus mereka lakukan di tempat kerja sehingga risiko K3 dapat diminimalkan. Kegiatannya terdiri dari (1) Merencanakan, menetapkan tujuan dan proses yang diperlukan untuk memberikan hasil sesuai dengan kebijakan $\mathrm{OH}$ \& S organisasi; (2) Melakukan, melaksanakan proses; Check, monitor dan mengukur kinerja terhadap kebijakan $\mathrm{OH} \& \mathrm{~S}$, tujuan, persyaratan hukum dan lainnya, dan melaporkan hasil; (4) Act, mengambil tindakan untuk terus meningkatkan kinerja OH\&S. Pangkey et al., (2012) mengungkapkan tentang dalam melakukan penelitian mengenai kajian penerapan SMK3 pada Proyek Konstruksi di Indonesia. SMK3 telah direncanakan dan diterapkan dengan baik di lokasi proyek. Standar dan pedoman yang digunakan untuk mengatur sistem ini disusun dalam Rencana Mutu, Keselamatan dan Kesehatan Kerja serta Lingkungan Proyek (RMK3LP). Dasar penerapan prosedur-prosedur tersebut disesuaikan dengan standar internasional yaitu Occupation Health and Safety Management System (OHSAS) 18001:1999 yang memiliki kesamaan dengan SMK3 diatur dalam Peraturan Menteri Tenaga Kerja Nomor: PER.05/MEN/1996. Penerapan SMK3 ini membawa pengaruh yang baik bagi perusahaan maupun tenaga kerja, hal tersebut terlihat dari jumlah tenaga kerja yang mengalami kecelakaan atau penyakit kerja masih tergolong rendah dan tidak memberikan pengaruh yang berarti bagi pelaksanaan pekerjaan.

Selain itu penelitian Syamtinningrum, (2017) dalam penelitian mengenai pengembangan model hubungan faktor personal dan manajemen K3 terhadap tindakan tidak aman pada pekerja PT Yogya Indo Global. Berdasarkan hasil penelitian 
menunjukkan bahwa dua indikator faktor personal (pengetahuan dan pelatihan K3) dan manajemen $\mathrm{K} 3$ memiliki pengaruh negatif yang signifikan dengan tindakan tidak aman (unsafe action). Sedangkan dua indikator faktor personal lainnya (beban kerja dan kelelahan) memiliki pengaruh positif yang signifikan terhadap unsafe action. Oleh karena itu, peneliti tertarik untuk meneliti pengaruh implementasi SMK3 terhadap unsafe action di PT EGS Indonesia.

\section{METODE}

Penelitian ini dilaksanakan di PT EGS Indonesia yang beralamat di daerah Kemayoran, Kecamatan Gunung Sahari Selatan, Jakarta Pusat Propinsi DKI Jakarta. Lokasi ini dipilih penelitian karena PT EGS merupakan salah satu perusahaan yang sudah menjalankan sistem manajemen keselamatan kesehatan kerja sesuai dengan regulasi yang berlaku

Penelitian menggunakan metode wawancara dan observasi. Pengumpulan data penelitian pada Agustus-Desember 2020. Jenis penelitian yang digunakan bersifat deskriptif kuantitatif untuk mendeskripsikan sistem pelaksanaan kesehatan keselamatan kerja terhadap upaya penekanan unsafe action. Pendekatan yang digunakan adalah cross sectional. Rancangan cross sectional dipilih karena pendekatannya suatu waktu dan tidak diikuti terus menerus selama kurun waktu tertentu.

Sumber data primer didapatkan melalui hasil observasi, angket (kuesioner) yang berisi beberapa pertanyaan yang harus dijawab oleh responden. Sumber data sekunder diperoleh dari buku-buku literatur, laporan dan sumber lainnya. Data sekunder adalah berupa data HSE statistik di PT EGS Indonesia dalam tiga tahun terakhir. Data tersebut berupa data QHSE Performance di PT EGS Indonesia 2016-2018.

Metode pengumpulan data primer dilakukan dengan menggunakan metode kuesioner yang bertujuan untuk mendapatkan data gambaran dari fenomena yang sedang diteliti. Wawancara dilakukan untuk menambah informasi yang dibutuhkan terkait penelitian dan yang mendukung penjelasan tentang data sekunder, sehingga peneliti lebih memahami objek dan karakteristik perusahaan yang diteliti.

Metode pengambilan sampel yang digunakan dalam penelitian ini adalah sampling jenuh (sensus) yaitu teknik pengumpulan data sampel jika semua anggota populasi digunakan sebagai sampel. Hal ini dilakukan karena jumlah populasi relatif sedikit. Dalam penelitian ini metode analisis data yang digunakan adalah structural equation modeling (SEM) dengan menggunakan software AMOS. Rangkaian proses pengolahan data meliputi pengujian model pengukuran (measurement model), meliputi validitas dan reliabilitas, sementara pengujian model struktural (structural model) meliputi uji signifikansi pengaruh variabel independen atau eksogen terhadap variabel dependen atau endogen.(Siswoyo, n.d.).

Adapun variabel yang akn akan diukur meliputi variabel independen seperti kepemimpinan dan kebijakan (LEA), perencanaan (PLA), pelaksanaan (PRO), evaluasi kinerja (EVA), tindakan perbaikan (ACT) serta variabel dependen yaitu tindakan tidak aman (UNS).

\section{HASIL}

PT. EGS Indonesia atau disebut juga PT EGSI telah menetapkan, mendokumentasikan, menerapkan dan memelihara Sistem Manajemen Kesehatan Keselamatan Kerja (K3) dan terus meningkatkan keefektifannya sesuai dengan persyaratan ISO 45001:2018, untuk meningkatkan kinerja kesehatan dan keselamatan kerja, (Anam, 2015). Dalam hal ini, perusahaan telah melakukan berbagai hal penerapan sistem manajemen kesehatan keselamatan kerja yaitu dengan; 1) mengidentifikasi proses yang diperlukan untuk sistem manajemen kesehatan, keselamatan kerja (K3) dan penerapannya di seluruh organisasi; 2) menentukan urutan 
dan interaksi dari proses-proses aktivitas; 3) menetukan kriteria dan metode yang diperlukan untuk memastikan bahwa operasi dan pengendalian aktivitas efektif; 4) Memastikan ketersediaan sumber daya dan informasi yang diperlukan untuk mendukung operasi dan pemantauan proses-proses; 5) secara aktif mencari umpan balik pelanggan mengenai kinerja sistem kesehatan keselamatan kerja; 6) memantau, mengukur dan menganalisa proses-proses, dan 7) melaksanakan tindakan yang diperlukan untuk mencapai hasil yang direncanakan dan perbaikan terus menerus dari proses.

Perusahaan telah menentukan ruang lingkup sistem manajemen kesehatan keselamatan kerja berdasarkan beberapa hal diantaranya; 1) isu internal dan eksternal yang mengacu pada klausul 4.1; 2) persyaratan pihak berkepentingan yang relevan yang mengacu pada klausul $4.2 ; 3$ ) kegiatan yang berhubungan dengan pekerjaan, produk dan layanan organisasi yang dilakukan; 4) batasan dari sistem manajemen K3 yang disebutkan diatas; 5) pemberlakuan sistem manajemen $\mathrm{K} 3$ yang disebutkan di atas; 6) kewajiban penaatan yang dimaksud pada klausul 4.2 ; 7) unitunit, fungsi-fungsi dan batasan-batasan fisik organisasi; 8) kewenangan dan kemampuan PT EGS Indonesia untuk melakukan pengendalian dan memberikan pengaruh.

Rangkaian proses pengolahan data meliputi pengujian model pengukuran (measurement model), meliputi validitas dan reliabilitas, sementara pengujian model struktural (structural model) meliputi uji signifikasi pengaruh variabel independen atau eksogen terhadap varabel dependen atau endogen. Tabel 2 menyajikan nilai SLF dari masing-masing variable independen yang diukur seperti LEA, PLA, PRO, EVA, ACT dan UNS. Jumlah indikator dari variabel LEA sebanyak 4 indikator. Seluruh nilai SLF dari masingmasing indikator $>0,5$. Hal ini menunjukkan bahwa sifat convergent validity yang baik telah dicapai dari sisi ukuran SLF. Jumlah indikator dari variabel PLA sebanyak 3 indikator. Seluruh nilai SLF dari masing-masing indikator $>0,5$. Hal ini menunjukkan bahwa sifat convergent validity yang baik telah dicapai dari sisi ukuran SLF.

Tabel 2. Nilai SLF Berdasarkan Indikator Variabel LEA, PLA, PRO, EVA, ACT dan UNS

\begin{tabular}{cc}
\hline Indicator & Standardized Loading Factor \\
\hline LEA1 & 0.97 \\
LEA2 & 0.972 \\
LEA3 & 0.975 \\
LEA4 & 0.964 \\
PLA1 & 0.976 \\
PLA2 & 0.97 \\
PLA3 & 0.964 \\
PRO1 & 0.931 \\
PRO2 & 0.975 \\
PRO3 & 0.962 \\
PRO4 & 0.964 \\
EVA1 & 0.975 \\
EVA2 & 0.964 \\
EVA3 & 0.975 \\
ACT1 & 0.975 \\
ACT2 & 0.963 \\
ACT3 & 0.975 \\
UNS1 & 0.969 \\
UNS2 & 0.96 \\
UNS3 & 0.966 \\
UNS4 & 0.969 \\
UNS5 & 0.954 \\
UNS6 & 0.963 \\
UNS7 & 0.966 \\
UNS8 & 0.962 \\
\hline
\end{tabular}

Jumlah indikator dari variabel PRO sebanyak 4 indikator. Seluruh nilai SLF dari masing-masing indikator $>0,5$. Hal ini menunjukkan bahwa sifat convergent validity yang baik telah dicapai dari sisi ukuran SLF. Jumlah indikator dari variabel EVA sebanyak 3 indikator. Seluruh nilai SLF dari masing-masing indikator $>0,5$. Hal ini menunjukkan bahwa sifat convergent 
validity yang baik telah dicapai dari sisi ukuran SLF. Jumlah indikator dari variabel ACT sebanyak 3 indikator. Seluruh nilai SLF dari masing-masing indikator $>0,5$. Hal ini menunjukkan bahwa sifat convergent validity yang baik telah dicapai dari sisi ukuran SLF. Jumlah indikator dari variabel UNS sebanyak 8 indikator. Seluruh nilai SLF dari masing-masing indikator $>$ 0,5. Hal ini menunjukkan bahwa sifat convergent validity yang baik telah dicapai dari sisi ukuran SLF. Selanjutnya akan dilakukan pengujian hipotesis, yakni apa LEA, PLA, PRO, EVA, ACT berpengaruh signifikan atau tidak terhadap UNS. Tabel 3 disajikan hasil pengujian hipotesis.

Tabel 3. Pengujian Hipotesis

\begin{tabular}{lllrrrrl}
\hline & & & $\begin{array}{r}\text { Estimat } \\
\text { e }\end{array}$ & $\begin{array}{r}\text { S.E } \\
.\end{array}$ & C.R & P & Labe \\
1
\end{tabular}

Berdasarkan hasil AMOS pada Tabel 3, dapat diketahui bahwa LEA berpengaruh negatif terhadap UNS, dengan nilai koefisien jalur $-0,180$, dan signifikan, dengan nilai $\mathrm{P}=0,011<0,05$. Selanjutnya PLA berpengaruh negatif terhadap UNS, dengan nilai koefisien jalur $-0,177$, dan signifikan, dengan nilai $\mathrm{P}=$ $0,010<0,05$. Selain itu PRO berpengaruh negatif terhadap UNS, dengan nilai koefisien jalur $-0,195$, dan signifikan, dengan nilai $\mathrm{P}=0,010<0,05$. Untuk EVA berpengaruh negatif terhadap UNS, dengan nilai koefisien jalur $-0,161$, dan signifikan, dengan nilai $\mathrm{P}=0,021<0,05$. Adapun ACT berpengaruh negatif terhadap UNS, dengan nilai koefisien jalur $-0,183$, dan signifikan, dengan nilai $\mathrm{P}=$ $0,014<0,05$.
Tabel 5. Koefisien Determinasi

\begin{tabular}{|l|r|}
\hline & Estimate \\
\hline UNS & .489 \\
\hline
\end{tabular}

Diketahui nilai koefisien determinasi dari UNS adalah 0,489 yang berarti pengaruh LEA, PLA, PRO, EVA, ACT terhadap UNS sebesar 48,9\%, sisanya sebesar $51,1 \%$ dipengaruhi oleh faktor lainnya. Berdasarkan hasil analisis data menggunakan metode SEM diatas dapat diketahui bahwa Sistem Manajemen Keselamatan Kesehatan Kerja (SMK3) yang berdasarkan ISO 45001 memiliki pengaruh terhadap unsafe action.

\section{PEMBAHASAN}

Dari hasil pengolahan analisis data, dimana seluruh nilai SLF dari masingmasing indikator $>0,5$. Hal ini menunjukkan bahwa sifat convergent validity yang baik telah dicapai dari sisi ukuran SLF

Dari hasil pengolahan analisis data diperoleh nilai koefisien jalur $-0,180$, dan signifikan dengan nilai $\mathrm{P}=0,011<0,05$. Hal ini berarti ada pengaruh negatif antara manajemen K3 dalam hal ini kepemimpinan dan kebijakan terhadap tindakan tidak aman (unsafe action). Adapun dari hasil observasi dan wawancara di lapangan, manajemen perusahaan sudah sangat fokus dan aware terhadap pelaksanaan implementasi K3 baik dikantor pusat maupun di site. Adapun tingkat risiko dikantor pusat tidak setinggi dengan risiko yang ada di lapangan, maka untuk itu dilakukan safety talk dan management visit yang bertujuan untuk meningkatkan wawasan pekerja dalam kepedulian terhadap budaya K3 di lapangan. Sistem manajemen K3 mengharuskan setiap top manajemen secara berkala melaksanakan manajemen visit ke tempat kerja untuk berkomunikasi langsung dengan pekerja dalam mesosialisasikan kebijakan perusahaan seerta mencari solusi dalam temuan kejadian unsafe condition maupun unsafe action yang ada di lapangan. Oleh karena itu top manajemen selalu 
melaksanakan hal tersebut sebagai bentuk komitmen top manajemen kepada pekerja.

Dari hasil pengolahan analisis data diperoleh nilai koefisien jalur $-0,177$, dan signifikan dengan nilai $\mathrm{P}=0,010<0,05$. Hal ini berarti ada pengaruh negatif antara manajemen $\mathrm{K} 3$ dalm hal ini perencanaan terhadap tindakan tidak aman (unsafe action). Berdasarkan hasil observasi dilapangan, perencanaan K3 sudah dilaksanakan oleh PTEGSI dengan baik. Proses SMK3 dimulai dengan suatu proses perencanaan yang baik dalam menjamin penerapan K3 sesuai dengan kebijakan dan sasaran yang diinginkan. Hasil ini senada dengan penelitian, (Nujhani \& Juliantina, 2013) yang menyatakan bahwa di PT. Pupuk Sriwidjaja sudaha ada perencanaan K3 yang diterapkan untuk mengendalikan potensi bahaya di tempat kerja. Pada dasarnya persyaratan SMK3 dalam penyusunan rencana K3 dalam ISO 45001 menyatakan bahwa tujuan dan sasaran harus memenuhi kriteria yang dapat diukur dan ada sasaran pencapaian dan jangka waktu diharapkan oleh perusahaan serta indicator penilaian dalam pengukuran pencapaian rencana K3 yang diinginkan.

Dari hasil pengolahan aanlisis data diperoleh nilai koefisien jalur $-0,195$, dan signifikan dengan nilai $\mathrm{P}=0,010<0,05$. Pelaksanaan K3 merupakan tahap yang paling penting dalam penerapan SMK3, dimana sukses dan tercapainya program kerja yang telah dibuat oleh perusahaan jika dalam pelaksanaan di lapangan tidak dilakukan dengan baik dan konsisten maka tidak akan dapat memberikan hasil yang optimal. Penerapan K3 juga memerlukan pelaksana K3 yang dapat memahami mengenai SMK3 diterapkan oleh PTEGSI. Menurut penelitian (Nujhani \& Juliantina, 2013) di Pupuk Sriwidjaja, bahwa di perusahaan pelaksanaan rencana K3 sudah dilakukan, Dimana perusahaan telah menempatkan personel yang mempunyai kualifikasi yang dibutuhkan seperti Ahli K3 dan operator-operator mesin yang bersertifikat. Perusahaan juga telah memiliki prosedur pendokumentasian dan pengendalian dokumen. Perusahaan hanya perlu memantau pelaksanaannya dilapangan sehingga benar-benar memberikan hasil yang diharapkan.

Nilai koefisien jalur $-0,161$, dan signifikan dengan nilai $\mathrm{P}=0,021<0,05$. Adapun dalam implementasi evaluasi kinerja dari SMK3, PT EGSI melakukan dengan melaksanakan internal audit sehingga SMK3 tersebut dapat terukur dan menjadi acun dalam upaya pengendalian pencegahan unsafe action yang terjadi dilapangan. Selain itu, PT EGSI melakukan evaluasi kinerja oleh top manajemen pada periode tertentu untuk memastikan apakah penerapan SMK3 sudah sesuai dan efektif dengan yang diharapkan oleh perusahaan. Dimana dalam penelitian (Dan et al., 2013) di proyek pembangunan Siloam Hospital bahwa pemantauan dan evaluasi kinerja sudah dilakukan. Audit internal dibuat berdasarkan hasil evaluasi K3.

Nilai koefisien jalur $-0,183$, dan signifikan dengan nilai $\mathrm{P}=0,014<0,05$. Hal ini berarti ada pengaruh negatif antara manajemen $\mathrm{K} 3$ dalm hal ini tindakan perbaikan terhadap tindakan tidak aman (unsafe action). Hasil penelitian di PTEGSI menunjukkan bahwa tindakan perbaikan sudah dilakukan. Proses akhir dari SMK3 adalah tindakan perbaikan dari hasil audit maupun evaluasi kinerja yang telah dilakukan sebagai upaya dalam pencegahan terjadi sutu tindakan unsafe action maupun unsafe condition yang terjadi di lapangan. Menurut Nujhani \& Juliantina (2013) di PT. Pupuk Sriwidjaya menyatakan bahwa peninjauan dan peningkatan kinerja K3 sudah dilakukan. Perusahaan telah melakukan rapat tinjauan ulang secara berkala. Dalam mencapai penerapan SMK3 yang optimal, diperlukan tindakan perbaikan yang komprehensif dan terintegrasi dengan seluruh langkah pengendalian yang dilaksanakan serta berbagai pendekatan sehingga potensi bahaya dan risiko dalam perusahaan dapat diminilisir. 


\section{KESIMPULAN}

Berdasarkan hasil penelitian yang dilakukan, maka dapat diambil kesimpulan bahwa pelaksanaan Sistem Manajemen Keselamatan Kesehatan Kerja (SMK3) yang dilaksanakan oleh PT EGS Indonesia telah menerapkan sesuai standar yang telah ditentukan. Standar yang diadopsi berdasarkan ISO 45001:20018 dengan pendekatan Plan do Check Action (PDCA). Secara Keseluruhan Sistem Manajemen Keselamatan kesehatan Kerja (SMK3) berupa kepemimpinan dan kebijakan, perencanaan, pelaksanaan, evaluasi kinerja dan tindakan perbaikan memiliki pengaruh negative terhadap tindakan tidak aman (unsafe action)(Heckman et al., 1967).

Berdasarkan hasil analisis penelitian, maka dapat di rumuskan beberapa saransaran terkait, dimana perlu adanya pengawasan dan edukasi secara konsisten kepada seluruh pekerja yang beraktivitas agar senantiasa untuk selalu mengikuti peraturan yang diterapakan perusahaan khususnya dalam hal sistem manajemen Keselamatan Kesehatan Kerja (SMK3) dalam beraktifitas. Demikian hasil dari penelitian yang bisa penulis sampaikan, terima kasih.

\section{UCAPAN TERIMAKASIH}

Terimaksih pada semua pihak yang telah membantu pada proses penelitian ini sehingga penelitian ini dapat diselesaikan dengan baik dan semoga berguna

\section{DAFTAR PUSTAKA}

Anam, K. (2015). Hubungan Antara Pengetahuan, Sikap Dan Iklim Dengan Perilaku Keselamatan Kerja Pada Karyawan Unit Spinning V Pt . Sinar Pantja Djaja Semarang Tahun 2015. 102.

BSI ISO. (2018). BSI Standards Publication BS ISO 45001: 2018 Occupational Health and Safety Management Systems Requirements with Guidance for Use.

Dan, K., Kerja, K., Pada, S. M. K., \& Akhir, T. (2013). ( Studi Kasus : Siloam

Hospital di Jln . Imam Bonjol Medan )

PROGRAM PENDIDIKAN SARJANA

EKSTENSI EVALUASI PENERAPAN

SISTEM MANAJEMEN

KESELAMATAN DAN KESEHATAN

KERJA ( SMK3 ) PADA ( Studi Kasus :

Siloam Hospital di Jln . Imam Bonjol

Medan ).

Government Regulation Number 50. (2012). Application of the Workplace Safety and Health Management System. Application of the Workplace Safety and Health Management System, 21(3), $1-27$.

Juliantina, I. (2013). Evaluasi Penerapan SMK3 di PT. Pupuk Sriwidjaya. Jurnal Universitas Sriwijaya, 1(3), 80-85

Kementerian Tenaga Kerja. (2012). Sistem Manajemen Keselamatan dan Kesehatan Kerja. In Permenaker Nomor 5 (Vol. 2, Issue 2).

Masjuli. (2018). Akselerasi Sosialisasi ISO 45001:2018 Tentang Sistem Manajemen Keselamatan Kesehatan Kerja. Jurnal Migrasian, 6(1), 19-24

Nujhani, J., \& Juliantina, I. (2013). Evaluasi Penerapan Sistem Manajemen Keselamatan dan Kesehatan Kerja (SMK3) pada Proyek Persiapan Lahan Pusri IIB PT. Pupuk Sriwidjaja Palembang. Jurnal Teknik Sipil Dan Lingkungan, 1(1), 80-85.

Pangkey, F., Malingkas, G. Y., \& Walangitan, D. O. R. (2012). Penerapan Sistem Manajemen Keselamatan Dan Kesehatan Kerja (Smk3) Pada Proyek Konstruksi Di Indonesia (Studi Kasus: Pembangunan Jembatan Dr. Ir. Soekarno-Manado). Jurnal Ilmiah MEDIA ENGINEERING, 2(2), 100-113.

Pusat, K., Jendral, J., Kav, S., Fax, T.,

Pendirian, A., No, P., Sianturi, J. M., Jakarta, S. H., Setiawan, N., Jakarta, S. H., \& Wna, W. N. I. (n.d.).

Kementerian Energi Dan Sumber Daya Mineral Direktorat Jenderal Minyak 
Dan Gas Bumi Kemampuan Usaha Penunjang Migas Pt. Asia Petrocom Services. 30.

Puji, Ari, Andriyas. (2016). Pengaruh Keselamatan dan Kesehatan Kerja Terhadap Produktivitas Menggunakan Structural Equation Modeling. Jurnal Fakultas Teknologi Industris, 1(2), 111

Purwanto, A., Asbari, M., \& Santoso, P.B. (2019). Pengaruh Kompetensi,

Motivasi, Kepemimpinan, Komitmen dan Budaya Kerja Sistem Manajemen Integrasi ISO 9001, ISO 14001 Pada Industri Otomotif. Jurnal Produktivitas, 6(1), 158-166

Putera, R.I., \& Harini, Sri. (2017). Pengaruh Keselamatan dan Kesehatan Kerja (K3) Terhadap Jumlah Penyakit Kerja dan Jumlah Kecelakaan Kerja Karyawan Pada PT. Hanei Indonesia. Jurnal Visionida, 3(1), 42-53

Rahayu, Endang Purnawati. (2015).

Hubungan Antara Pengetahuan, Sikap dan Perilaku Karyawan Dengan Penerapan Manajemen Budaya Keselamatan dan Kesehatan Kerja Di Bagian Produksi PT Mustika Ratu. Jurnal Kesehatan Komunitas, 2(6), 289-293

Rizka Pisceliya, D. M., \& Mindayani, S. (2018). Analisis Kecelakaan Kerja Pada Pekerja Pengelasan Di Cv. Cahaya Tiga Putri. Jurnal Riset Hesti Medan Akper Kesdam I/BB Medan, 3(1), 66. https://doi.org/10.34008/jurhesti.v3i1.2 5

Syamtinningrum, M. D. P. (2017).

Pengembangan Model Hubungan Faktor Personal Dan Manajemen K3 Terhadap Tindakan Tidak Aman (Unsafe Action) Pada Pekerja PT. Yogya Indo Global. Institut Teknologi Sepuluh Nopember Surabaya, 57-90.

UU RI Nomor 1 Tahun 1970. (1970).

Undang-undang Republik Indonesia

Nomor 1 Tahun 1970 Tentang

Keselamatan Kerja. 